\title{
Analyzing the Mainland Chinese People's Taiwan-Bound, Self-Guided Tours: Do They Provide a Window of Chance for the Development of Taiwanese Tourism Industry?
}

\author{
Peng-Hsiang Kao ${ }^{1}$ \\ ${ }^{1}$ Department of Food \& Beverage Management, China University of Science and Technology, Taiwan
}

Correspondence: Peng-Hsiang Kao, Associate Professor, Department of Food \& Beverage Management, China University of Science and Technology, No. 245, Academia Rd, Sec.3, Nangang Dist,Taipei 11581, Taiwan. Tel: 886-2-2528-8316. E-mail: seankao@mail2000.com.tw

Received: January 21, 2015

Accepted: April 10, 2015

Online Published: May 4, 2015

doi:10.5430/jms.v6n2p31

URL: http://dx.doi.org/10.5430/jms.v6n2p31

\begin{abstract}
The greatest difference between "self-guided tours" for mainland Chinese in Taiwan, kicked off at June 2011, and the currently dominant "group-in, group-out" tourism model lies in the fact that the former dispenses with travel guides and thus allows Chinese tourists to freely choose their desired itineraries and accommodations, which in turn breaks the monopoly of a few service providers in the mainlanders-reliant tourism market. By way of interviewing and literature review, this study's author attempted to summarize the positive and unknown effects of Taiwan's policy concerning the deregulation of mainlanders' self-guided tours. The last part of this study offers government authorities some policy-oriented recommendations in this regard.
\end{abstract}

Keywords: self-guided tours, outbound tourism, mainland Chinese tourists

\section{Introduction}

Outbound tourism is a topic of interest for tourism researchers as it has significant economic, social, cultural and political effects on both parties involved in international tourism. (Note 1) Many scholars consider mainland Chinese tourists' traveling in Taiwan a topic of interest more valuable theoretically than any other case of outbound tourism worldwide, citing the long-time separation of, and political rivalry between, Taiwan and China. The purpose of this study is to address the effects of deregulating individual mainlanders' tours of Taiwan (i.e., self-guided tours) on the Taiwanese tourism industry.

Thanks to recent economic booms and political deregulations in China, more and more mainlanders are capable of, or can afford, trips to Taiwan. China's history of outbound tourism began somewhere around late 1980s, when the mainlanders were allowed to visit their relatives in Hong Kong or Macau. The extent of deregulation has since been increasing over the years. (Note 2) The Chinese deregulation of self-guided tours to Hong Kong and Macau starting 2003 brought revenues and also a series of challenges to both outlying regions. (Note 3) What worried people in Hong Kong and Macau the most was their over-dependence on mainland China would result in a fragile regional economy that is hit harder by financial crises than any inland Chinese province. (Note 4) Similarly, the influx of mainland tourists could be mixed news for Taiwan, considering its effects on the island region.

Concerns over legalizing mainlanders' self-guided, Taiwan-bound tourism are reflected in the Taiwanese policies, which stick to the principle that mainland Chinese shall always visit Taiwan in groups, or the "group-in, group-out" approach adopted in a multi-phase manner. In 2001, Type 1 mainland Chinese tourists (i.e., Chinese nationals living in Hong Kong or Macau) became the first category of mainlanders permitted to visit Taiwan, followed by Type 2 (i.e., Chinese nationals traveling abroad for pleasure or business purposes) and Type 3 (i.e., Chinese nationals with permanent residency permits issued by countries other than China). In 2006, the China National Tourist Office (CNTO), the Ministry of Public Security and the Taiwan Affairs Office of the State Council jointly enacted the "Measures for the Administration of the Travel of Mainland Residents to the Taiwan Region," which provide that mainland Chinese tourists visit Taiwan through CNTO-approved travel agencies in a "group-in, group-out" manner, with the total number of tourists controlled by a quota system. Moreover, a Chinese travel agency offering group tours in Taiwan must sign a contract with a Taiwanese travel agency that helps the mainland tourists with their trips 
to the island. (Note 5)

As a matter of fact, Taiwanese hospitality service providers have been earnestly expecting further deregulation ever since the "group-in, group-out" approach was implemented; they even exerted pressure on the public sector for that reason. (Note 6) However, there were several obstacles to the deregulation of mainlanders' Taiwan-bound, self-guided tours. First of all, the Taiwan government was afraid that such self-guided tours may deepen Taiwan's economical dependence on China. Taiwan as a substantive sovereignty is independent in terms of national defense, diplomacy and internal affairs, (Note 7) but the legalization of mainlanders' self-guided tours could result in greater economic dependence on China, with the undermined independence spreading from the economic to the political arena. Secondly, the Taiwanese authorities were worried that too many Chinese nationals would stay in Taiwan beyond the predetermined period of self-guided tours.

After years of debates among policymakers, nevertheless, Taiwan and China have built a consensus over the deregulation of mainlanders' self-guided, Taiwan-bound tourism because, firstly, many experts considered it unwise for Taiwan to say no to economic profits for political concerns. Professor Huei Kao from the National Quemoy University said, "Self-guided tours not only give mainlander Chinese a relatively realistic understanding of Taiwan but also contribute to the cross-strait peace progress; they will not affect Taiwan's security". (Note 8) Some Taiwanese tourism service providers contended that tourism/hospitality and politics should be addressed separately. (Note 9) As for the worry that the self-guided tourism could trigger a surge in Chinese runaways (from tours groups), a Tourism Bureau official noted, "Over the first five months in 2009, only two mainlanders escaped from the tour groups while traveling in Taiwan, which is an insignificant percentage". (Note 10)

Taiwan redoubled efforts to negotiate with China over the self-guided tours after both concerns mentioned above were clarified. According to the timetable, the Straits Exchange Foundation (SEF) and the Association for Relations Across the Taiwan Straits (ARATS) were supposed to hold talks on the "Measures for the Administration of the Travel of Mainland Residents to the Taiwan Region," with the concluded measures carried out by the Chin-based Association For Tourism Exchange Across The Taiwan Straits (ATETS), in association with the Taiwan-based Taiwan Strait Tourism Association (TSTA). (Note 11) In fact, ATETS and TSTA are considered informal representatives (or the "white-gloved" people) of CNTO and Tourism Bureau as a majority of their workers had assumed important positions in the latter two. While the mainlanders' self-guided, Taiwan-bound tourism is conducted by ATETS or TSTA to reduce the political sensitivity across the Taiwan Strait, (Note 12) opinions differed on the exact time of deregulation. Some newspaper articles said Lai Shin-yuan, Minister of the cabinet-level Mainland Affairs Council (MAC), declared that mainlanders' self-guided tours would be available as soon as April 2011 in the Kinmen and Matsu archipelagos, or the prioritized "trial zones". (Note 13) Taiwan's Premier Wu Den-yih said such deregulation policy would be implemented no later than July 1, 2011 or perhaps June. (Note 14) Using a reserved tone, the Tourism Bureau official said he was unsure about the deregulation time because he had not been notified by MAC in this regard. (Note 15) The Chinese authorities, however, announced the launch of Taiwan-bound self-guided tours on June 27. Generally speaking, the decision of offering self-guided tours to mainland Chinese was highly complicated and involved far more factors than offering group-only tourism.

On the face of it, mainlanders' self-guided tours and "group-in, group-out" tours in Taiwan both belong in the category of outbound tourism, but they differ drastically in nature. The mainlanders are currently allowed to visit Taiwan, despite the challenging amount of restrictions. Take group-only tourism for example, the minimum size of a valid Taiwan-bound tour group is reduced to five members, who are allowed to spend a third of the time in Taiwan doing whatever they please. The problem is, mainland tourists must tell the travel guide(s) where they plan to visit or stay in Taiwan and, when necessary, report travel plans to Taiwanese authorities (i.e., MAC, National Police Agency, Tourism Bureau and National Immigration Agency) in an onerous procedure. (Note 16) Although mainlanders' business trips to Taiwan dispense with travel guides and consequently enjoy greater flexibility, the Taiwan government requires that proper documentation be produced for such business trips, making it unlikely for all mainland Chinese to visit Taiwan following this particular model. (Note 17)

The legalization of self-guided tours is a sign that all mainlanders are able to travel in Taiwan as they please, without pre-determined itineraries or travel guides. The clearly defined plans of group-only tourism, on the other hand, allow Taiwanese hospitality service providers to control the itineraries, destinations and accommodations before the arrival of mainlanders, which often result in the clustering of parties with particular interests. Free from the restrictions on itineraries, self-guided tours will probably spark a tourism market shake-up, and subsequently affect the development of Taiwanese economy and society as a whole. Previous literature in this regard either addressed Chinese tourists' impact on Taiwan's overall political and economic development, (Note 18) or was focused on their economic 
benefits. (Note 19) On the basis of a literature review, this study attempts to explore the nature and effects of mainlanders' self-guided tours on the overall Taiwanese tourism industry, using a research methodology that involves newspaper articles and related publications, besides interviews with more than 10 representatives from the industry, government and academia. The author analyzed the information collected and made policy-oriented recommendations regarding mainlanders' Taiwan-bound, self-guided tourism.

\section{The Nature and Effects of Mainlanders' Self-guided Tours in Taiwan: The 'Positive Effects' and 'Unknown Effects'}

What exactly is the impact of mainland Chinese people's self-guided tourism on the overall Taiwanese socio-economic development? The best answer to that question would be: the self-guided tours bring a hint of suspicion and uncertainties despite their obviously positive effects on Taiwan. To be specific, the positive effects include fairer competitions in the tourism market and refined travel services; the unknown effects include a crowding-out between Chinese and non-Chinese travelers in Taiwan, besides the influx of Chinese funding.

From the tourism perspective, self-guided tours belong in the category of "outbound tourism," the theoretical discussions of which are often focused on two questions: why a tourist chooses to visit a certain place and what the actual revenues a hospitality service provider earns from a certain destination (of outbound tourism). As for the first question, previous literature suggested that a tourist usually determines travel destinations according to the physical, cultural, interpersonal and status motivators. (Note 20) When it comes to the second question, studies show that developing tourism has a sizable effect on the regional economy, industries and culture (e.g., the balance-of-payments, the qualitative/quantitative improvements of work force in the hospitality sector, and the multiplier effect on tourism). (Note 21)

For mainland Chinese, there is a greater significance underlying their Taiwan-bound, self-guided tourism than a typical trip of "outbound tourism". Simply put, outbound tourism is mostly resulted from economically oriented thinking, but Taiwan's policy of offering mainlanders self-guided tours is made under the framework of both culturally and politically oriented concerns. The self-guided tours for mainland Chinese can be addressed in three tangible dimensions, namely cultural/linguistic similarities, economic-profit distribution, and the concerns over anti-R.O.C. propaganda.

Firstly, the cultural and linguistic similarities across the Taiwan Strait make Taiwan a highly attractive sightseeing destination for mainland Chinese, giving them a huge cultural motivator regarding Taiwan. (Note 22) Some Chinese tourists said spending the Chinese New Year in Taiwan was a heartwarming experience because Taiwan and China share the same cultural/racial background, customs and dietary habits. (Note 23) Compared to group-only tourism, self-guided tours allow mainlanders to make closer observations of the amazing Taiwanese culture. While the pre-determined itinerary and schedule of group travel that makes long stays at a specific location unlikely, service providers in the self-guided tourism model do not determine the itinerary beforehand and the mainland tourists have to make almost all decisions during their trips, hence the extra opportunities to savor the beauty of Taiwanese society and culture. However, the mainlanders will not really enjoy the amenities of self-guided tours until the Taiwanese authorities and tourism sector introduce more supportive measures. (Note 24)

One probable result of the cultural/racial similarities across the Taiwan Strait is that Taiwanese businesses would lower the percentage of non-Chinese customers in order to lure mainlanders: they prefer doing business with the former because of the fewer difficulties in direct communications. (Note 25) What makes mainland Chinese tourists so different from non-Chinese ones is the linguistic and cultural similarities between Taiwan and China, which allow Taiwanese businesses to do commercial transactions effortlessly with the mainlanders.

The second dimension to mainlanders' Taiwan-bound, self guided tours is the economic-profit distribution. Undeniably, mainland Chinese tourists benefit the Taiwanese economy tremendously, but the restricted tour prices, destinations and itineraries in the group-only tourism model often give a few particular companies a monopolistic hold on customer sources, hence the unevenly distributed tourism resources. Another problem is that the "group-in, group-out" model puts a cap on the tour package prices, triggering a cutthroat competition among service providers and subsequently hindering their efforts to improve services. Since self-guided tourism more closely resemble the free competition emphasized in a free market than group-only tourism, the upcoming tourism-market situation would possibly be determined by market forces.

The final dimension to mainlanders' Taiwan-bound, self guided tours is the concern over anti-R.O.C. propaganda. Ever since it became an emerging economy, China has frequently offering economic aid to third-world countries by way of outbound tourism. In other words, outbound tourism is a tool of the Chinese authorities to support certain 
countries/regions. Considering CNTO's limited decision-making power in outbound tourism, the diplomatic authorities of China play a centric role in this regard. (Note 26) The use of state power to strictly define travel destinations is noticeable particularly in Chinese policies governing Taiwan-bound tourism.

China denies that it has a nation-to-nation relationship with Taiwan, which adds difficulties to cross-strait tourism talks. Jia Qinglin, chairman of the National Committee of the Chinese People's Political Consultative Conference (CPPCC), once noted that cross-strait tourism is not nation-to-nation in nature, clearly signaling a political framework. (Note 27) The ATETS in charge of mainlanders' Taiwan-bound tourism is a policy-executing agency in nature, rather than an independent policymaker; the policy-making power actually rests in those involved in the negotiations between ARATS and SEF. An official of Taiwan's Tourism Bureau agreed that, throughout the policy-making process, the Tourism Bureau has constantly been in talks with SEF to determine if the cross-strait situation is favorable enough for mainlanders' self-guided, Taiwan-bounded tourism. (Note 28) The policy-making process has far more implications than tourism: it has much to do with China's strategic deployment for its warfare against Taiwan, as well as the political concerns of Taiwanese authorities.

Also adding to the policy's complexity is the ideological rivalry between Taiwan's ruling Kuomintang (KMT) party and the opposition Democratic Progressive Party (DPP). (Note 29) When Taiwan was under the DPP rule, the party's rationale about China-related policies resulted in a limited probability of mainlanders visiting Taiwan. (Note 30) Another crucial factor behind the restrictions on mainlanders' Taiwan-bound, self-guided tours is that China managed to prevent the deregulation from lifting the then-ruling DPP's approval rating during a period of political transition. (Note 31) The number of mainland Chinese tourists visiting Taiwan has been rising noticeably since President Ma Ying-jeou took office. Mainland Chinese tour groups accounted for more than 1.2 million tourist arrivals in the year 2010, with that figure expected to hit the 3 million mark. Janice Lai, Director-General of Taiwan's Tourism Bureau, urged a re-assessment of the quota system as the 2,000/day upper limit might not meet the unexpected growth in mainlanders' demand for trips to Taiwan. (Note 32) The Taipei office of ATETS was launched in May 2010 to handle mainlanders' tours of Taiwan (Note 33), a sign of the thriving cross-strait tourism in the Ma administration, as well as how the number of tourist arrivals from mainland China is closely linked to Taiwan's internal political dynamics.

The discussions above show that the policies and implementation of mainlanders' self-guided tours in Taiwan are inevitably affected by cultural, economic and political factors, which prompted this study's author to simplify the analysis topic into four aspects, namely the fair competition in tourism market, the refinement of travel services, the crowding-out effect of Chinese tourists traveling in Taiwan, and the influx of Chinese funding. While the first two factors exert positive effects on Taiwan's tourism industry, the latter two are bound to occur. Figure 1 is the analytical framework of these factors:

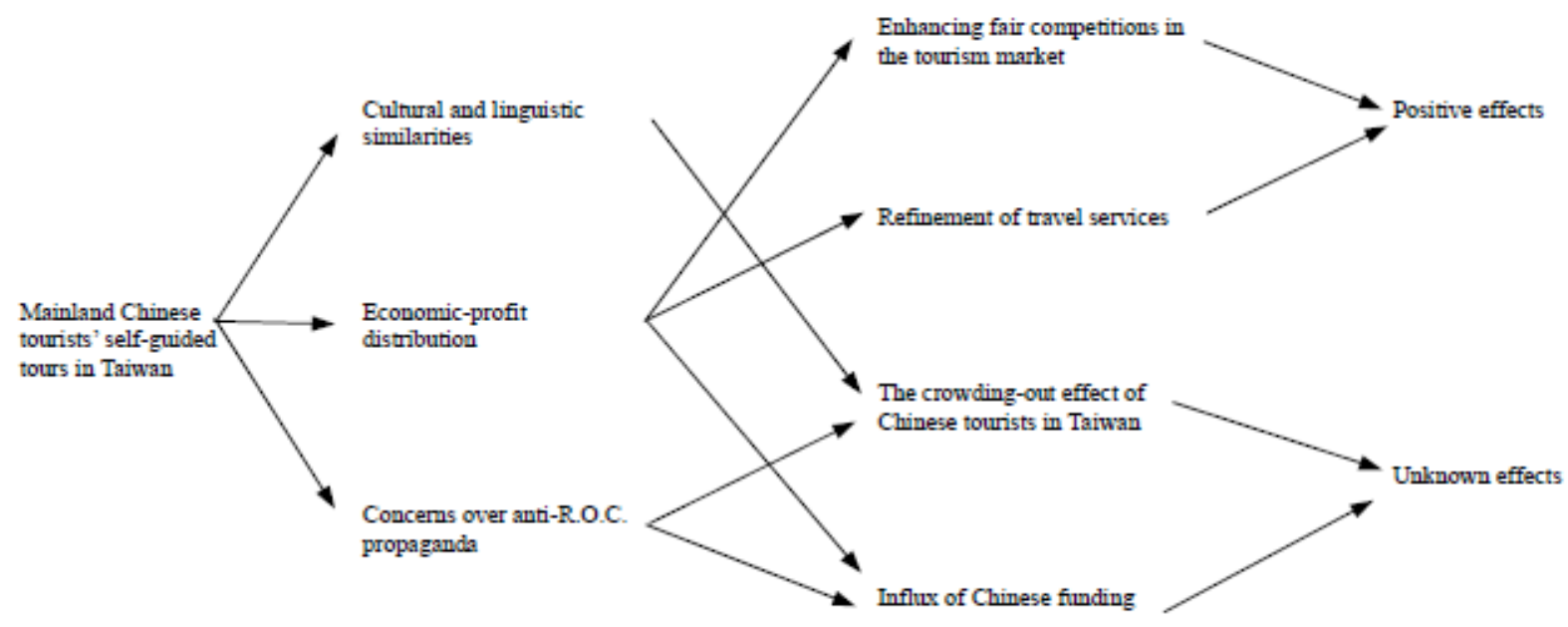

Source: The author

Figure 1. An analytical framework for the effects of mainlanders' self-guided tourism in Taiwan

\section{The First Positive Effect: Enhancing Fair Competition in the Tourism Market}

The first positive effect of deregulating Chinese people's self-guided, Taiwan-bound tours is ensuring fair competition in the tourism market. The current "group-in, group-out" operating model makes it easier for large-sized 
travel/leisure service providers to win Chinese customers through a marketing mechanism. As the deregulation of mainlanders' self-guided tours increases the opportunities for small-sized travel/leisure service providers to reach out to Chinese tourists, fair competition in the tourism market would be achieved with the dissolving of large companies' monopoly. Some scholars said the deregulation, especially in the early stage, would surely give small companies access to a part of the customer base. (Note 34) There were hospitality firms predicting that, if the occupancy of renowned Taiwanese hotels that most mainland Chinese choose to stay in reach full capacity, the minor accommodation facilities will enjoy a share of the profits. (Note 35)

Under the group-only tourism scheme, large travel/leisure companies have the greatest access to customer base because of their competitiveness in sales channels, marketing and brand awareness. Mainlanders traveling in Taiwan prefer prestigious, large-sized hotels because they are status symbols. (Note 36) Also, tourism resources are relatively accessible for large-sized hospitality firms. Take Kinmen for instance, the implementation of Mini Three Links left airline tickets in the control of large travel agencies and often unavailable to the minor ones. (Note 37) Hospitality/recreational services at mainlanders' must-visit attractions such as Sun Moon Lake and Alishan are usually monopolized by a few companies. The group-only tourism mechanism allows large companies to plan itineraries and travel destinations in advance. Ming-chung Wang, an Alishan-based tourism service provider said,

"Now the mainlanders are usually arranged to stay in a hotel near the Chung Tai Buddhist Temple on their way from the Sun Moon Lake; almost all Chinese tourists stay in that hotel. After visiting Alishan and the neighboring attractions, the tour group returns directly to the parking lot before heading downhill for the hotel. There are only two hotel options: the Jianfusan Prince Hotel and Chinatrust Hotel's Chiayi branch. As a matter of fact, these hotels have to work closely and directly together with travel agencies in order to benefit from the crowds of tourists!" (Note 38)

In addition to the monopolistic power of travel agencies and accommodation facilities, Taiwanese travel agencies would cut the cost of trip planning with pre-determined itineraries. The legalized self-guided tourism, on the other hand, makes it possible not only for mainland Chinese to follow their desired itineraries without the arrangement of travel agencies, but also for less-renown attractions to lure mainlanders. Saying that "most Chinese people know no more than Alishan, Sun Moon Lake or the Zhiben Hot Spring in Taitung," Chien-han He, a hot-spring facility owner in Taipei, called the self-guided tourism a rather fair deal for all Taiwanese companies involved as it adds less-known attractions to the mainlanders' itineraries. (Note 39)

Another benefit of the self-guided tourism stems from the fact that it encourages the mainland Chinese to choose accommodations at locations that are not pre-determined, bringing extra revenues to the usually less-popular attractions. Studies show economic benefits vary even among the attractions popular with mainlanders. Currently, the accommodation facilities for a standard 8-day, 7-night round-the-island tour are concentrated in six attractions (i.e., northern Taiwan, Taichung, Sun Moon Lake, Alishan, Kaohsiung, Taitung and Hualien), making the profits hardly shared by similar facilities in the other regions. (Note 40) For convenience reasons, Chinese tourists almost always buy souvenirs near lodging facilities in the above-mentioned regions, which is something unfair for gift shops elsewhere. For example, most mainlanders visiting Taiwan pick up pineapple cakes, a must-buy, at the Chia-Te Bakery when they spend the night in Taipei, even if the snack is available in many prestigious bakeries island-wide. Because the relatively expensive room rates discourage mainlanders-reliant travel agencies from making Kenting a lodging option, Chi-kuang Chang, who offers accommodations in Kenting, said it is hardly possible for Kenting stores to lure mainlanders into shopping frequently there. He added that the sales results of Kenting-produced pineapple cakes, among other souvenirs, will improve if mainland tourists spend one more night in the area. (Note 41)

It is worth noting that the authorities have to introduce supportive measures in order to break the market monopoly by means of self-guided tourism, or large travel agencies would regain monopolistic access to the customer base with a competitive marketing team, making this emerging market segment once again fall under the control of a few interest groups. Hsi-dong Chiou, a tourism service provider based in Hualien County, offered a gloomy view on whether the self-guided tours would lead to a tourism market of fair competition. He said,

"No matter where they come from, tourists in Taiwan now follow plans controlled by the travel agencies in every aspect, from the accommodations, shopping, sightseeing, to the other itinerary details. The deregulation of self-guided tours may slightly increase the mainland tourists' degree of independence, but the principles will basically be intact. Although there might be some changes to dining, accommodations or attractions in the itinerary, $I$ think the basic rules will be scarcely changed. Those who are able to secure orders will always do so, and those who aren't would probably not get much of a market share". (Note 42) 
Some experts argued that, even if small travel/leisure companies are given access to customer base shortly after the self-guided tourism is deregulated, it remains to be seen whether that profitability will last over the long term. (Note 43) The Taiwan government is urged to re-examine several policies in order to break monopoly in the market. First of all, a one-stop service for mainland Chinese visiting Taiwan should be in place, with every local business given access to potential customers or deal-making opportunities. If a mainlander asks for comprehensive consultancy through the one-stop service before visiting Taiwan, the Taiwanese companies will be able to offer services as requested. According to a Taiwanese hot-spring facility owner, the township office in his neighborhood had been considering starting an "alliance of inexpensive tourism services," where hospitality firms with sound operations obtain information about one another from a government-initiated website, and then join forces to offer extra options to mainland Chinese tourists. (Note 44) Some companies even expressed willingness to uphold the government website's reputation by paying for its services, fearing that under-qualified companies registering online free of charge could tarnish the website's image. (Note 45)

As for the second policy concern, greater publicity should be given to small companies or counties/cities less visited by the mainland Chinese. Taiwan's tourism authorities at county/city levels are advised to raise the awareness of minor travel agencies and hotels by launching "collective marketing" campaigns in China, or by promoting less-known Taiwanese scenic spots in films. (Note 46) Some local business owners, however, said the effectiveness of local governments' collective marketing efforts remain to be seen, because they could end up attracting mainlanders who wish to visit as many attractions in a short time as possible, without even paying attention. Instead, these business owners are inclined to promote products via China's non-government platforms or travel websites. (Note 47)

It is possible that mainlanders' self-guided tours would encourage fair competitions among Taiwanese travel/leisure companies, thwarting the large conglomerates' control over business opportunities in the "group-in, group-out" model, and subsequently shake up the current market. Something worth noting is that, large companies will probably leverage their competitive resources and marketing prowess to gain monopolistic access to the emerging customer segment of mainlanders' self-guided tours. Consequently, the Taiwan government should do its best to bolster the publicity of small companies in the tourist market targeting mainland Chinese people, so mainlanders will be sufficiently informed in a market of fair competition.

\section{The Second Positive Effect: Refinement of Travel Services}

The second effect of deregulated self-guided tours is the further refinement of travel services for mainland Chinese in Taiwan. The strictly imposed price caps under the group-only tourism scheme forced Taiwanese firms to attract mainlanders with a low-priced strategy. Self-guided tours, on the other hand, do not have to abide by the much-emphasized price caps, which in turn makes it easier to offer refined tourism services.

A negative effect of group-only tourism is the cutthroat competition that forces tourism companies to keep the tour price under a certain level. The minimum reception rate announced by Taiwan's Tourism Bureau (i.e., US\$ 60 per person per day for mainland Chinese tour groups) not only failed to deter travel agencies taking the low-price strategy, but also hindered efforts to improve services. That is why the high-priced, upscale facilities became less popular. Despite the minimum rate set by Tourism Bureau, a hospitality service provider said, mainland Chinese travel agencies had already engage in cutthroat competitions to make their offers more attractive, which forced their Taiwanese counterparts to follow the low-price strategy and offer tour package at a daily rate as low as US\$ 28 to US\$ 30 per person. (Note 48) Such a pricing policy would surely result in poor-quality tourism services. Some of the local companies complained that mainlanders-reliant hotels cut room rates drastically because the Chinese tourists did not spend as much money in Taiwan as expected. The increased sales may not necessarily drive up the profits from Chinese customers, they added. (Note 49)

Because of the strategic cutthroat competition, inexpensiveness rather than good services became the sole emphasis of group-only tourism. Citing the example of catering industry, a consultant for hospitality facility said in an interview for this study, "The cutthroat price war in Taiwan's market for package tours targeting mainlanders has been insanely intensified, making it almost impossible for the island to establish a culinary culture that is one of a kind". Although the increasing tourist arrivals from mainland China in recent years did not seem to encourage improvements in catering services, the removed tour-price caps due to the deregulation of mainlanders' self-guided tourism will hopefully incentivize Taiwanese companies to develop uniquely styled food. (Note 50)

In the absence of a cap on tour prices, the model of self-guided tourism would bring profits to a wider range of hospitality firms that include 5-star hotels, themed guesthouses, luxury motels, recreational farms, high-end restaurants, and ethnic eateries. (Note 51) Whether Chinese tourists can afford these costly amenities depends on 
their spending power. A backpacker or student from mainland China, for instance, will find the travel costs unaffordable. From the perspective of tourism market, self-guided tours helps build a more comprehensive pricing mechanism, where products are provided according to each Chinese tourist's budget. That is, the tour packages will break out of the mid-to-low price range, with high-priced products/services starting to attract mainlanders. (Note 52)

Providers of travel services that feature Taiwan's cultural distinctiveness are another potential beneficiary of the deregulated self-guided tourism. It is worth noting that none of the Taiwanese attractions is scenically distinctive (particularly when compared to those in China), so Taiwan would never be able to attract Chinese tourists with natural phenomena. Yu Chang, who offers tourism services at Sun Moon Lake, said many Chinese tourists are disappointed about the much-touted scenery of Taiwan. In order to impress mainlanders, he called on the government to give Taiwanese attractions a total makeover, and offer them in tour packages that underscore the sophisticated cultural elements native to Taiwan. (Note 53) According to Hui-wen Sun, a Kinmen-based tourism service provider, the scenery of Kinmen is nothing compared to China's magnificent Jiuzhaigou Valley or Yellow River, but it has the potential of being developed into tourist spots that are one of a kind, such as the military relics. Sun suggested that an amusement park similar to the Disney World or Universal Studios be built in Kinmen to lure Chinese people traveling from Xiamen to Fuzhou. (Note 54)

Taiwan is believed to attract the mainland Chinese with its abundant cultural resources after the deregulation of self-guided tours. For example, Taiwan boasts a tea-tasting culture that is no less elegant or sophisticated than the Japanese one. Given Chinese tourists' curiosity about the Taiwanese tea ceremony, tea parlors such as those in Maokong could profit from mainlanders' self-guided tours with just the right amount of promotional efforts and comfortable services. Night markets, historic streets, among other cultural highlights unique to Taiwan with a potential to attract mainlanders (especially the less-known ones), would also offer Chinese backpackers with extra destination options. (Note 55) Moreover, tourism companies' marketing efforts will, to a certain extent, turn Meinong's signature oil-paper umbrellas into something attractive to the mainland Chinese. (Note 56)

The other potential beneficiaries of mainlanders' self-guided tours include medical cosmetology clinics and wedding photographers. The former have been offering tourism-oriented medical services for years with advanced technologies, and started targeting Chinese tourists when they were allowed to legally visit Taiwan two years ago, encouraged by the absence of language barriers. The deregulation of self-guided tourism is expected to spark another wave of Chinese people visiting Taiwan for health screenings and/or cosmetology treatments. (Note 57) Chiou-liang $\mathrm{Hu}$, who offers tourism services in the Zhiben hot spring zone, believed it would be easy to lure mainlanders into taking wedding photos against the backdrop of Taiwan's scenic beauty, citing the popularity of Taiwanese photographers in mainland China. (Note 58) The Tourism Bureau official agreed that Taiwanese cosmetology clinics and wedding photography are both well acclaimed in China. With the bureau's ongoing promotional efforts, he hoped both industries would enjoy further growth after the legalization of mainlanders' self-guided tours. (Note 59)

The deregulation of self-guided tours will also prompt Taiwanese transportation firms to improve services eagerly. Tour buses are hardly available for mainland Chinese traveling in Taiwan, making transportation services that connect tourist attractions very important. In fact, some accommodation facilities in Taiwan already offer concierge taxi services to business travelers from mainland China. (Note 60) Taiwan boasts a highly accessible inter-city transportation network, but the shuttle busing that connects major attractions (e.g., Sun Moon Lake, Alishan and Kenting) await improvements. After the deregulation of Chinese visitors' self-guided tours in Taiwan, accommodation facilities should work more closely together with transportation service providers to offer better services. (Note 61) A Tourism Bureau official said many hotels had signed contracts with taxi and busing companies for training programs, in hopes of meeting the market demand for services stemming from self-guided tours. Apparently, Taiwanese travel service providers are sensitive to business potential in an energetic private sector. (Note 62)

Simply put, another positive effect of mainlanders' self-guided tours would be the refined tourism services, because the removal of price caps for group-only tourism helps high-priced travel service providers widen their customer bases. The lack of scenic distinctiveness, nevertheless, makes it imperative that the government or private companies offer refined cultural highlights in a package with special services, in order to attract mainlanders. Chinese tourists will enjoy more in-depth, culture-oriented tours or advanced technologies/services in Taiwan when their self-guided tours are legalized and itineraries deregulated. The brand-new opportunities arising from such deregulation will not only create a free market mechanism out of the tourism sector targeting mainland Chinese, but also improve Taiwan's tourism industry as a whole. 


\section{The First Unknown Effect: The Crowding-out Effect of Chinese Tourists Traveling in Taiwan}

It is difficult to evaluate the pros and cons of mainlanders' self-guided tours in Taiwan, considering their potential consequences. This study's author addresses those consequences as two "unknown effects," the first one being the crowding-out effect of mainland tourists, which means cultural/linguistic similarities across the Taiwan Strait encourage Taiwanese companies to offer services to mainlanders and develop a business model catering to their needs, with non-Chinese customers neglected. Because Japanese visitors have greater spending power than the Chinese ones, DPP once warned against the unwise decision for Taiwan to lure Chinese tourists while overlooking the non-Chinese ones. (Note 63) The question is: will mainlanders' self-guided, Taiwan-bound tours really trigger a crowding-out effect? If yes, how are the Taiwanese authorities supposed to tackle that effect?

The potential crowding-out effect may imply that Taiwanese tourism companies, troubled by the limited resources, are unable to meet the needs of all customers and, instead, decide to win customers from a particular market segment, or conduct market segmentation. (Note 64) Given the cultural and linguistic similarities across the Taiwan Straits that give them little problem communicating with mainlanders, Taiwanese companies find it easier to lure mainland Chinese tourists than non-Chinese ones. After weighing the costs against profits, they are likely to change the business model into one that targets Chinese tourists and seek the so-called "mainlanders-reliant economy" while considering non-Chinese visitors secondary targets. That would discourage non-Chinese tourists from visiting Taiwan, hence the crowding-out effect.

According to a source in the tourism industry, Taiwanese travel service providers are taking two different approaches to business. Those taking the quantity-oriented approach fully embrace the China market and spend all their resources on luring Chinese tourists, showing no concern for the overall service quality of Taiwanese travel sector. On the other hand, travel service providers taking the quality-oriented approach do not believe the massive influx of Chinese tourists in a short period of time helps reach the industry's long-term goal. The industry source added that, currently, tour buses in Taiwan are concentrated in the mainlanders-reliant market segment and hardly available even to Taiwanese people on domestic trips. (Note 65) She predicted the Chinese visitors' self-guided tours in Taiwan will trigger a crowding-out effect on non-Chinese tourists, and subsequently worsen the shortage of hospitality facilities.

The authorities and private companies disagree over whether Chinese tourists have a crowding-out effect on non-Chinese ones. Citing statistics from the past few years, a Tourism Bureau official noted an increase in tourist arrivals from both China and non-Chinese regions, proving the absence of a crowding-out effect. In the long run, mainlanders would not consume tourism resources at the expense of the wellbeing of non-Chinese visitors. From the perspective of market economy, Taiwanese tourism service providers will voluntarily replenish the transportation equipment and lodging facilities required to meet the needs of mainlanders, (Note 66) and decide whether they should keep doing business with them in a market mechanism.

Quite a number of tourism service providers believe that Chinese tourists will not necessarily have a crowding-out effect on non-Chinese ones. A hot-spring guesthouse owner said the unsavory practices mainland visitors were once notorious for (e.g., talking out loud in public, being selfish or uncivilized) are now found only in senior citizens, and the youngsters are actually quite disciplined. She does not believe in the crowding-out effect of Chinese tourists on the other customer segments. (Note 67) Compared to Japanese visitors, she said those from mainland China would "ask for a sickening amount of discounts and favors," which however is a quality found also in people from the Taiwanese countryside. Dismissing the possibility of negative effects, she actually expects mainlanders' self-guided tours to stimulate the Taiwanese tourism market. (Note 68) According to a hotel consultant, the Grand Hyatt Taipei now unconditionally welcomes Chinese tourists it once found repugnant. (Note 69) These opinions suggest that Chinese tourists will not necessarily have a crowding-out effect on non-Chinese ones, and Taiwanese companies will make independent decisions in their own interests.

However, there are Taiwanese companies holding a reserved attitude toward the mainlanders' self-guided, Taiwan-bound tours. A guesthouse proprietor, for one, said he would choose to receive Chinese tourists when their self-guided tours in Taiwan were legalized, although he would determine the next steps after continuous observations. He showed an inclination to say no to Chinese tourists if their sub-standard behaviors affect the rights of non-Chinese ones. (Note 70) Some companies said the relatively uncivilized practices of mainlanders might drive up the costs/expenses of maintaining the quality of travel services. Ming-chung Wang, who offers tourism services in the Alishan area, cited the example that specialists are stationed at mainland Chinese scenic spots to monitor the tourists' behaviors, as evidenced in the special staff that prevents visitors from littering on the premises of 5-star hotels. He suggests that the Taiwan follow these good examples. (Note 71) As highly civilized tourists from Europe, the U.S., Japan and Taiwan do not need any of these control measures, Taiwanese hospitality companies' attempt to 
win mainland Chinese customers while maintaining the quality of services will probably cost them extra money.

Results of the interviews show that not all Taiwanese tourism companies believe in the crowding-out effect triggered by deregulation of mainlanders' self-guided tours. A large number of them actually are convinced that they will be able to win Chinese tourists without neglecting the non-Chinese ones, which prompted this study's author to suspect that the discussions of crowding-out effect are significantly swayed by political ideologies, with opinions varying among Taiwanese private companies.

From the perspectives of politics or national security, nevertheless, there is some value in DPP's worry about the crowding-out effect, although it is too early to tell if such an effect will occur. Should the services for Chinese tourists are offered at the expense of the wellbeing of non-Chinese ones, with Taiwanese tourism resources concentrated in the customer segment of mainland Chinese, something worrisome may occur to the Taiwanese economy and society as a whole. Ching-sung Lee, who heads the Department of Restaurant, Hotel and Institutional Management at $\mathrm{Fu}$ Jen Catholic University, warned Taiwan against "putting all the eggs in one basket". Taiwan should pay equal attention to non-Chinese tourists from across Asia, so as to avoid the risks of a tourism industry excessively dependent on mainland China, he added.

"Attention should be paid to every customer segment of the tourism market, including domestic travelers. It is unwise to focus on the pie (promised by mainlanders' self-guided tours in Taiwan). As we all know, the China market is never a stable one and, to a large extent, swayed by the policy makers. Any negative impact of changes in China's tourism policy would cost Taiwan a huge market, and subsequently affect non-Chinese tourists visiting Taiwan from across Asia". (Note 72)

The cross-strait tourism market is characterized by a relatively high degree of uncertainty as it is under the threat of political instability. If Taiwan makes the "mainlander-reliant economy" its sole pursuit, it will concentrate tourism resources in a specific customer segment and, consequently, add to the risks of investments. When there is a change in cross-strait situation that keeps mainlanders from visiting Taiwan, the Taiwanese tourism market will suffer a serious blow due to excessive dependence on mainlanders.

\section{The Second Unknown Effect: The Influx of Chinese Funding}

The second unknown effect of mainlanders' self-guided, Taiwan-bound tours is the influx of Chinese funding, which is being tightly restricted by Taiwanese regulations and put under scrutiny. Take the tourism sector for example, mainland Chinese financiers are allowed to invest in Taiwan's hospitality facilities but Chinese shareholders are prohibited at large amusement parks. (Note 73) Judging from the eagerness of mainlanders in investing in Taiwan, whether there will be deregulations following the legalization of mainland Chinese people' self-guided tours would inevitably make an impact on the Taiwanese economic market and national security. The ongoing trends indicate that Chinese financiers are highly interested in investing in Taiwan, and may do so with various justifications. According to a recent rumor circulating in the tourism sector, Chinese financiers are enthusiastic about acquiring a Taiwanese travel agency. (Note 74) Even if the Taiwan government legalizes mainlanders' self-guided tours, it remains uncertain whether it would approve the massive influx of Chinese funding.

Chinese financiers are extremely interested in the Taiwan market, particularly in the markets for real estate and luxury goods, according to statistics. Many Chinese retailers of luxury watches, for example, are opening stores in Taiwan because they expect profits from mainlanders' self-guided, Taiwan-bound tours, and also because luxury watches are $20 \%$ cheaper in Taiwan than in China. The greatest concentration of China-based luxury watch stores is found in the much-coveted $4^{\text {th }}$ section of Zhongxiao E. Road, where the HENGDELI Group, a typically China-funded timepiece retailer, bought a storefront for a record-breaking NT\$ 905 million. A well-funded conglomerate, HENGDELI is China's largest luxury watch distributor/retailer. It has opened 302 retail stores in China, Hong Kong and Taiwan (including 35 stores in Taiwan). Chien-hsing Li, a real estate agent, said the influx of China-based companies underscores the tremendous effect of mainlanders' self-guided, Taiwan-bound tours. (Note 75)

There are several reasons that prompted Chinese companies to invest in Taiwan's luxury goods market. First of all, luxury goods are cheaper than those in China; secondly, luxury goods sold in Taiwan appear more reliable because people have a greater chance of buying fake watches in China, where counterfeits are ubiquitous. (Note 76) That is, mainland Chinese companies are keen to open designer goods stores in Taiwan. It is interesting that the Chinese firms would probably make investments in Taiwan, and then take away a part of mainland tourists' money spent in Taiwan by selling them products during their stays in Taiwan. (Note 77) These factors fueled the interest of Chinese companies in selling luxury goods in Taiwan. 
Likewise, China-based service providers are interested in making investments in Taiwan. Take the catering industry for example, both the Quan-ju-de Roast Duck Restaurant and Tanyutou Restaurant consider launching operations in Taiwan because of the similarities between Taiwan and China in culinary culture, and also because of their motive to acquire commercial skills from the Taiwanese service sector, which boasts world-class quality and a degree of sophistication higher than its Chinese counterparts. That explains why Chinese service providers may set up operations in Taiwan, and learn from the island's widely acclaimed business model in the process. (Note 78)

Chinese financiers are highly interested in the real estate of Taiwan, which is a better residential area than the densely populated Hong Kong and thus attracts high-income business owners across mainland China. Citing "living environment" the primary factor behind mainlanders' property purchase plans in Taiwan, Xiaosu Meng, director of the China National Real Estate Development Group Co. (CRED), said the good living environment is what lures wealthy Chinese to buy luxury houses in Taiwan. As long as its employees and money are allowed to freely move across the Taiwan Strait, the CRED will invest not only in Taipei, but also in Taichung and Kaohsiung, Meng noted. (Note 79)

The deregulation of mainlanders' self-guided, Taiwan-bound tours further incentivizes Chinese businessmen to invest in Taiwanese real estate. Meng said the Taiwan government announced in 2003 the permission for mainland Chinese to make real estate investments, but from the viewpoint of Chinese businessmen, that announcement was a mere gesture and gave no hint of welcome. In Meng's opinion, Taiwan does not have free access to Chinese funding, and consequently will not successfully lure Chinese businessmen until it meets at least two conditions: the unobstructed movements of mainland Chinese funding and personnel across the Taiwan Strait. (Note 80) The SRE Group chairman Jain Shi once vowed, "I'll buy 5, or even 10, golf courses in Taiwan so long as the mainlanders' self-guided tours are deregulated!" Through a representative, the China-based Country Garden real estate group also expressed willingness to foray into the Taiwanese real estate market by strategically partnering with the Far Glory Group (Note 81)

The legalization of mainland Chinese people' self-guided tours results in dramatically fewer restrictions on their entry into Taiwan, which in turn encourages them to make investments or real estate purchases in Taiwan. Although the concern over national security keeps the Taiwan government from legalizing investments by Chinese businessmen any time soon, Chinese funding may be approved by the authorities under various pretenses. The most common way to avoid Taiwanese regulatory challenges scrutiny, for example, is using the disguise of a Hong Kong company. (Note 82) Political factors are inevitably factored into the assessment of any economic activity, but the Taiwanese authorities might need to reconsider the necessity of repeatedly reiterating its political ideology to interfere in economic affairs, now that the Chinese funding is approved in Taiwan with all kinds of justifications.

Despite the spate of media reports on the prediction that mainlanders' Taiwan-bound, self-guided tours would encourage the influx of Chinese funding, concerns over national security prevents the Taiwan government from easily approving funding from across the strait. On the other hand, many scholars suggested that the authorities should make Taiwanese companies more competitive, rather than intervening in economic activities using political measures. Despite the spate of media reports on the prediction that mainlanders' Taiwan-bound, self-guided tours would encourage the influx of Chinese funding, concerns over national security prevents the Taiwan government from easily approving funding from across the strait. On the other hand, many scholars suggested that the authorities should make Taiwanese companies more competitive, rather than intervening in economic activities using political measures. They proposed an integration of Taiwanese and mainland Chinese markets in order to maximize profitability on both sides of the Taiwan Strait. After legalizing mainlanders' self-guided tours, the Taiwan government should deregulate Chinese financing in particular categories as a guidance provider, instead of sticking to the political ideology in passive defense, they added.

\section{Conclusions}

There is a large difference between mainland Chinese people's self-guided tours in Taiwan and the typical outbound tourism. During the interview process mentioned above, this study's author realized that such self-guided tourism is hampered by cultural, economic and political factors, making it a rare topic in the discipline of tourism research. Chinese tourists are attracted to Taiwan largely because of the cultural similarities across Taiwan Strait. While the money spent by mainland tourists in Taiwan contributes to the island's economy, the process of their visits to Taiwan is swayed by politics and full of uncertainties. To further delve into the issue, this study's author proposes the following recommendations to the authorities concerned:

1. Taiwan should expend the power of tourism authorities, which means the establishment of a Ministry of Tourism is imperative for the time being. 
The latest government reform plan initially included a "Ministry of Cultural Affairs and Tourism" created out of a merger between the Council for Cultural Affairs and the Tourism Bureau, but a "Ministry of Culture" was established instead, because there was a wide-spread worry that the culture-minded people and tourism-minded people might not agree with each other rationale-wise. (Note 83) This study's author believes that disagreements between the two types of people are of a moderate extent; they do not justify any attempt to keep the Tourism Bureau from being upgraded to the ministerial level. Currently, the Tourism Bureau belongs under the Ministry of the Interior and has limited power, hence the impossibility to handle mainlanders' Taiwan-bound tours independently. Given the restrictions stemming from cross-strait politics, mainlanders' Taiwan-bound, self-guided tourism remains full of uncertainties even if it is legalized, and therefore needs a governing body with greater power. Only by establishing the Ministry of Tourism and equipping it with the power of all authorities concerned will mainlanders' self-guided tours be effectively handled.

Introducing a Ministry of Tourism has a number of benefits regarding the effective handling of mainlanders' self-guided tours. First of all, Taiwanese tourism authorities at central and local levels have to redefine their respective governing duties when it comes to mainlanders' Taiwan-bound, self-guided tours. Currently, Taiwan's tourism affairs are overseen not only by the Tourism Bureau under the Ministry of Transportation and Communications (MOTC) at the central-government level, but also by county- or city-level Tourism Bureaus that rely mostly on the budget of local governments, which makes it questionable whether the MOTC's Tourism Bureau is able to effectively govern the local-level Tourism Bureaus. Once a Ministry of Tourism is in place at the central-government level, the Taiwanese tourism authorities will be given greater power and the authority to efficiently oversee county- or city-level Tourism Bureaus by means of personnel appointments. Secondly, the mainlanders' self-guided, Taiwan-bound tourism involves such central-level authorities as the National Immigration Agency, MAC, National Security Bureau, and several other cultural or economic authorities. To ensure efficient negotiations with these government agencies, it is imperative that the tourism authorities be given a higher hierarchical status.

The second recommendation proposed by this study's author is that the Taiwan government should assist tourism companies in sales and marketing. Among the viable ways to offer such assistance is a collective marketing mechanism that ensures mainland visitors receive sufficient information about companies from every level of Taiwan's tourism sector, so as to keep the emerging customer segment from being monopolized by the existing large companies. The government is also advised to launch mainlander-specific shopping districts that display products according to the Chinese tourists' preferences.

In the meantime, the Taiwan government should help tourism service providers with cultural marketing, so the regionally distinctive cultural attractions will be advertised as something attractive. For example, many Chinese tourists are interested in Kinmen's battlefield scenery, and the government may bundle revamped wartime tunnels with improved tourism facilities on the islet into a package that attracts mainland Chinese. (Note 84) Since investments in this regard required a sizable amount of funding besides professional planning, government interference in the form of consultancy will ensure the tourism sector fully demonstrate Taiwan's cultural and scenic beauty to mainlanders.

Without a doubt, the deregulation of mainlanders' self-guided tours offers the Taiwanese tourism market a "window of opportunities," and both the public and private sector are urged to take supportive measures concerning business opportunities and challenges arising from such self-guided tours as soon as possible. From political, economic and cultural perspectives, this study addressed the potential consequences of mainlanders' Taiwan-bound and self-guided tourism, identified two positive and two unknown effects of it, and then presented policy-oriented recommendations. All in all, the Taiwan government should give a higher hierarchical status to tourism authorities, make interventions in private-sector companies (in the form of consultancy), and face challenges more aggressively, in order to create additional business opportunities.

\section{References}

Anonymous author. (2007). A Not-So-Upbeat Outlook on Deregulating Chinese Tourists' Visiting Taiwan. The Commons Daily, 3 May, P. A5.

Anonymous author. (2010). Liu Zhijiang Appointed Head of ATETS' Taiwan Office. Ta Kung Pao, 19 August, p. A 20.

Anonymous author. (2010). Meng Xiaosu: Deregulation of Chinese People's Self-guided Tours in Taiwan Lures Chinese Financiers. Retrieved December 13, 2010, from http://www.haixiainfo.com.tw/128100.html 
Anonymous author. (2010). Shao Qiwei Expects 1.2 Mil Chinese Tourists to Visit Taiwan in 2010. Ta Kung Pao, 14 August, p. A19.

Anonymous author. (2011). Premier Wu: Mainlanders' Self-guided Tours in Taiwan to be Legalized No Later than Jul.1. TSSD News, 8 April, p. 3.

Anonymous author. (2011). Self-guided Tours for Mainlanders to be Available first in Kinmen and Matsu. The Commons Daily, 15 January, p. A4.

Chang, H.S. (2009, June). The Impacts of Policy Deregulation for Chinese Tourist on Taiwanese Tourism Industry. Taiwan Hospitality \& Tourism Journal, (6), 15-32.

Chen, W.H. (2011). How Much Longer Will Hong Kong's Economic Recovery Last? Hong Kong Commercial Daily, 7 January, p. A7.

Chiang, Y.H. (2006). Mainland Tourists' Arrival Benefits Taiwanese Tourism Sector Only to a Limited Extent. New Taiwan Weekly, Issue 526. Retrieved 20 April, from http://www.newtaiwan.com.tw/bulletinview.jsp? bulletinid $=24079$

Chiou, S.T. (2011). Mainlanders' Self-guided Tours Will Not Help Taiwanese Tourism If They Stay Dominated by Travel Agencies. The Independence Evening Post. Retrieved January 12, 2011, from http://www.idn.com.tw/news/news_content.php? catid=4\&catsid=5\&catdid=1\&artid=20110112richB002

Fan, S.P. (2005, June). A Policy Analysis on China's Tourism-based Diplomacy: A Case Study of Outbound Tourism Developments. Mainland China Studies, 48(2), 61-97.

Fan, S.P. (2010). A Political-Economic Analysis on the Impact of the Mainland Chinese Tourists Traveling to Taiwan on the Cross-Strait Relations. Taipei: Showwe Information Co., Ltd.

Fan, S.P. (2010, July). To Observe the Political Meaning of China's Policy Change on Taiwan Affairs from Chinese Tourist Arrivals to Taiwan. East Asia Studies, 41(2), 1-40.

Ghosh, R.N., Siddique, M.A.B., \& Gabby, R. (2003). International Tourism and Economic Development. In Ghosh, R. N., Siddique, M. A. B. and Gabby R. (Eds.), Tourism and Economic Development: Case Studies from the Indian Ocean Region (pp. 19-29). Adlershot: Ashgate.

Hashmi, S.H. (1997). Introduction. In Sohail H. Hashmi (Ed.), State Sovereignty: Change and Persistence in International Relations (pp. 1-14). University Park: Pennsylvania State University Press.

Hsu, C.H. (2007). Legalizing Chinese Tourists' Visiting Taiwan Should Never be an Empty Slogan. TSSD News, 27 May, p. 4.

Hu, C.L. (2011). A Thriving Mainlanders-Oriented Tourism Relies on Legalization of Self-guided Tours, Despite Growing Tourist Arrivals and Revenues. The Independence Evening Post. Retrieved January 4, from http://www.idn.com.tw/news/news_content.php? catid=4\&catsid=5\&catdid=1\&artid=20110104richB005

Jenkins, C.L., \& Liu, Z.H. (1997). China: Economic Liberalization and Tourism Development: the Case of the People's Republic of China. In Go, Frank M. Go and Carson L. Jenkins (Eds.), Tourism and Economic Development in Asia and Australasia (pp. 103-122). London; Washington, D.C.: Cassell.

Kao, H. (2010). Show Mainlanders How Wonderful Taiwan is through Self-guided Tours. China Daily News, 8 July, p. A2.

Li, K., \& Wang, Y. (2009). My Safe and Pleasant Trip to Taiwan during Chinese New Year. Guangxi Daily, 30 January, p.3.

Lin, B.L. (2009). Taiwan Should Follow Hong Kong's Example in Legalizing Mainlanders' Self-guided Tours in Taiwan. The Independence Evening Post, 21 April. Retrieved April 21, 2009, from http://www.idn.com.tw/news/news_content.php?catid=4\&catdid=1\&artid=20090421 charles001

Liou, H.T. (2009). Chinese Buyers Snatch up Taiwanese Housing Market before Legalization of Mainlanders' Self-guided Tours in Taiwan. Online edition of China Times. Retrieved May 10, 2009, from http://mag.chinatimes.com/mag-cnt.aspx?artid=671

McIntosh, R.W., Goeldner, C.R., \& Ritchie, J.R. (1990). Tourism: principles, practices, philosophies. New York, USA: John Wiley \& Sons Inc.

Ren, J.Y. (2005). The Effects of Self-guided Tours of Mainland-Chinese Tourists on Macau's Economy. China Statistics, (2), 58-59.

Richards, G. (2001). The Development of cultural tourism in Europe. In G. Richards (Ed.), Cultural Attractions and 
European Tourism (pp. 3-30). New York: CABI Publisher.

$\mathrm{Su}$, Y.Y. (2009). It is Unwise for Taiwanese Tourism Sector to Scare Away Non-Chinese Visitors while Luring Mainlanders. Liberty Times, 1 November, p. A2.

Sun, H.W. (2009). Developing Kinmen to Attract Chinese Financiers in Line with the Deregulation of Mainlanders' Self-guided Tours in Taiwan, IDN Living Travel Network. Retrieved July 17, 2009, from http://www.idn.com.tw/currect/content.php?catdid=6\&artid=20090717 $\mathrm{rich} 002$

Swarbrooke, J. (2007). Consumer Behaviour in Tourism. Amsterdam: Butterworth-Heinemann.

Tseng, H.R. (2009). Legalization of Self-Guided Tours Makes Chinese Tourists More Likely to Run Away After Arriving in Taiwan. The Liberty Times, 29 May, p. A8.

Wang, F.C. (2011). The Core Value of Chinese Tourists' Self-guided Tours Lies in Their Impressions of Taiwan. The Independence Evening Post. Retrieved January 24, 2009, from http://www.idn.com.tw/news/news_content.php?catid=4\&catsid=5\&catdid=1\&artid=20110124richA004

Wang, M.C. (2009). Mainland Tourists Take Taiwan's Commercial Activities Back to 2-decade-ago Level. The Independence Evening Post. Retrieved May 18, 2009, from http://www.idn.com.tw/news/news_content.php?catid=4\&catsid=5\&catdid=1\&artid=20090518charles001

Wang, S.M., \& Wen, P.C. (2010, July). The Economic Effects of Chinese Tourists on Taiwan Economy. Prospect Quarterly, 11(3), 133-175.

Wang, Y.H. (2011). Local Tourism Service Providers Weighing Business Potential and Equality of Mainlanders' Self-guided Tours in Taiwan. The Independence Evening Post. Retrieved January 23, 2011, from http://www.idn.com.tw/news/news_content.php?catid=4\&catsid=5\&catdid=1\&artid=20110123richA001

World Tourism Organization. (2007). Handbook on Tourism Market Segmentation-Maximising Marketing Effectiveness. Madrid: World Tourism Organization.

Wu, M.J. et al. (2009). Mainland Tourists Take Taiwan's Commercial Activities Back to 2-decade-ago Level. The Independence Evening Post. Retrieved May 18, 2009, from http://www.idn.com.tw/news/news_content.php?catid=4\&catsid=5\&catdid=1\&artid=20090518charles001

Wu, M.J. (2010). How Chinese People's Self-guided Tours in Taiwan is Closely Linked to the Taiwanese Tourism Sector. Liberty Times. Retrieved December 12, 2010, from http://www.idn.com.tw/news/news_content.php?catid=4\&catsid=5\&catdid=1\&artid=20101231 sarlin005

Xu, G. (1999). Tourism and Local Economic Development in China. Richmond, Surrey: Curzon Press.

Yang, Y. (2008, March). Political Factors in Taiwan's Liberalization of Mainland Residents Visit. East-Asia Review, (459), 11-22.

\section{Notes}

Note 1. Swarbrooke, John (2007). Consumer Behaviour in Tourism. Amsterdam: Butterworth-Heinemann.

Note 2. Jenkin,Carson L. and Liu,Zhen-Hua, "China: Economic Liberalization and Tourism Development: the Case of the People's Republic of China," in Go, Frank M. and Jenkins,Carson L. (eds), Tourism and Economic Development in Asia and Australasia (London; Washington, D.C.: Cassell, 1997), p.119.

Note 3. Ren, Jiayan (2005). The Effects of Self-guided Tours of Mainland-Chinese Tourists on Macau's Economy, China Statistics, Issue 2, pp.58-59.

Note 4. Chen, Wenhong (2011). How Much Longer Will Hong Kong's Economic Recovery Last? Hong Kong Commercial Daily, 7 January, p. A7.

Note 5. Chiang, Yan-huei (2006). Mainland Tourists' Arrival Benefits Taiwanese Tourism Sector Only to a Limited Extent, New Taiwan Weekly, Issue 526. Available at $<$ http://www.newtaiwan.com.tw/bulletinview.jsp?bulletinid=24079>. (Accessed: 20 April).

Note 6. A senior officer of the Tourism Bureau (A02). Interview, 12 April, 2012.

Note 7. Sohail H. Hashmi, "Introduction," in Sohail H. Hashmi ed. (1997). State Sovereignty: Change and Persistence in International Relations. University Park: Pennsylvania State University Press, p. 2.

Note 8. Kao, Huei (2010). Show Mainlanders How Wonderful Taiwan is through Self-guided Tours, China Daily News, 8 July, p. A2. 
Note 9. Lin, Bao-luo (2009). Taiwan Should Follow Hong Kong's Example in Legalizing Mainlanders' Self-guided Tours in Taiwan, The Independence Evening Post, 21 April. Available at <http://www.idn.com.tw/news/news_content.php?catid=4\&catdid=1\&artid=20090421 charles001>. (Accessed: 21 April 2009)

Note 10. Tseng, Hung-ru (2009). Legalization of Self-Guided Tours Makes Chinese Tourists More Likely to Run Away After Arriving in Taiwan, The Liberty Times, 29 May, p. A8.

Note 11. A Tourism Bureau specialist. Interview, 11 March 2012.

Note 12. A senior officer of the Tourism Bureau. Interview, 12 April 2012.

Note 13. Anonymous author (2011). Self-guided Tours for Mainlanders to be Available first Kinmen and Matsu, The Commons Daily, 15 January, p. A4.

Note 14 .Anonymous author (2011). Premier Wu: Mainlanders' Self-guided Tours in Taiwan to be Legalized No Later than Jul.1, TSSD News, 8 April, p. 3.

Note 15. A Tourism Bureau specialist. Interview, 11 March 2012.

Note 16. A senior officer of the Tourism Bureau. Interview, 12 April 2012.

Note 17. Mr. Shi, Deputy Manager of Pyramid International T/S Co. Interview, 13 May 2012.

Note 18. Fan, Shih-ping (2010). A Political-Economic Analysis on the Impact of the Mainland Chinese Tourists Traveling to Taiwan on the Cross-Strait Relations, Taipei: Showwe Information Co., Ltd.

Note 19. Chang, Hong-sheng (2009) The Impacts of Policy Deregulation for Chinese Tourist on Taiwanese Tourism Industry, Taiwan Hospitality \& Tourism Journal, June, Issue 6, pp.15-32; Wang, Shu-mei and Wen, Pei-chang (2010).The Economic Effects of Chinese Tourists on Taiwan Economy, Prospect Quarterly, July, Vol. 11, Issue 3, pp.133-175.

Note 20. The physical motivators prompt tourists to visit places where they can relax physically; the cultural motivators prompt them to visit places that meet their respective cultural preferences; the interpersonal motivators, places where they make friends and visit families; the status motivators, places that meet the needs for personal development (i.e., making business decisions and acquiring knowledge). Further discussions about the four types of motivators are found in McIntosh, R. W. Goeldner, C. R. and Ritchie, J. R. (1990). Tourism: Principles, Practices, Philosophies. New York, USA: John Wiley \& Sons Inc.

Note 21. Zu, Gang, Tourism and Local Economic Development in China (Richmond, Surrey: Curzon Press, 1999), p. 4.; Ghosh, R. N., Siddique, M. A. B. and Gabby, R., "International Tourism and Economic Development," in Ghosh, R. N., Siddique, M. A. B. and Gabby, R. (eds). Tourism and Economic Development: Case Studies from the Indian Ocean Region (Adlershot: Ashgate, 2003), pp. 19-29.

Note 22. For more discussions about cultural motivators, please refer to Richards, G. (2001). "The Development of cultural tourism in Europe," in Richards, G. (ed.), Cultural Attractions and European Tourism. New York: CABI Publisher, pp. 3-30.

Note 23. Li, Kai and Wang, Yan (2009). My Safe and Pleasant Trip to Taiwan during Chinese New Year, Guangxi Daily, 30 January, p.3.

Note 24. Wang, Fei-ching (2011). The Core Value of Chinese Tourists' Self-guided Tours Lies in Their Impressions of Taiwan, The Independence Avening Available $<$ http://www.idn.com.tw/news/news_content.php?catid=4\&catsid=5\&catdid=1\&artid=20110124richA004>.

(Accessed: 24 January 2011).

Note 25. Ms. Lu, souvenir retailer in Taipei. Interview, 25 February 2013.

Note 26. Fan, Shih-ping (2005). A Policy Analysis on China's Tourism-based Diplomacy: A Case Study of Outbound Tourism Developments, Mainland China Studies, Vol. 48, Issue 2, June, pp.61-97.

Note 27. Anonymous author (2007). A Not-So-Upbeat Outlook on Deregulating Chinese People' Taiwan-bound Tours, The Commons Daily, 3 May, P. A5.

Note 28. A senior officer of the Tourism Bureau. Interview, 12 April 2012.

Note 29. Yang, Yan (2008). Political Factors in Taiwan's Liberalization of Mainland Residents Visit, East-Asia Review, Issue 459, March, pp.11-22.

Note 30. Hsu, Chi-huang (2007). Legalizing Chinese Tourists' Visiting Taiwan Should Never be an Empty Slogan, 27 May, TSSD News, p. 4. 
Note 31. Fan, Shih-ping (2010). To Observe the Political Meaning of China's Policy Change on Taiwan Affairs from Chinese Tourist Arrivals to Taiwan, East Asia Studies, July, Vol. 41, Issue 2, pp.1-40.

Note 32. Anonymous author (2010). Shao Qiwei Expects 1.2 Mil Chinese Tourists to Visit Taiwan in 2010, Ta Kung Pao, 14 August, p. A19.

Note 33. Anonymous author (2010). Liu Zhijiang Appointed Head of ATETS' Taiwan Office, Ta Kung Pao, 19 August, p. A 20.

Note 34. Mr. Hsu, lecturer from a northern Taiwan university's Department of Tourism and Hospitality. Interview. 19 November 2012.

Note 35. Ms. Chang, hot-spring facility owner in the Jiaoxi area. Interview. 26 March 2013.

Note 36. Mr. Hsu, consultant of THE CARLTON hotel chain. Interview, 14 June 2012.

Note 37. Sun, Huei-wen (2009). Developing Kinmen to Attract Chinese Financiers in Line with the Deregulation of Mainlanders' Self-guided Tours in Taiwan, IDN Living Travel Network. Available at $<$ http://www.idn.com.tw/currect/content.php? catdid=6\&artid=20090717rich002>. (Accessed: 17 July 2009)

Note 38. Wu, Ming-jun et al. (2009). Mainland Tourists Take Taiwan's Commercial Activities Back to 2-decade-ago Level, The Independence Evening Post. Available at <http://www.idn.com.tw/news/news_content.php? catid $=4 \&$ catsid $=5 \&$ catdid $=1 \&$ artid $=20090518$ charles001 $>$ (Accessed: 18 May 2009).

Note 39. Wang, Yi-hua (2011). Local Tourism Service Providers Weighing Business Potential and Equality of Mainlanders' Self-guided Tours in Taiwan, The Independence Evening Post. Available at $<$ http://www.idn.com.tw/news/news_content.php? catid=4\&catsid=5\&catdid=.>

Note 40. Hu, Chiou-liang (2011). A Thriving Mainlanders-Oriented Tourism Relies on Legalization of Self-guided Tours, Despite Growing Tourist Arrivals and Revenues, The Independence Evening Post. Available at $<$ http://www.idn.com.tw/news/news_content.php?catid=4\&catsid=5\&catdid=1\&artid=20110104richB005>

(Accessed: 4 January)

Note 41. Mr. Yen, senior manager of Star Travel Co. Interview. 15 July 2012.

Note 42. Chiou, Shi-tung (2011). Mainlanders' Self-guided Tours Will Not Help Taiwanese Tourism If They Stay Dominated by Travel Agencies, The Independence Evening Post. Available at $<$ http://www.idn.com.tw/news/news_content.php?catid=4\&catsid=5\&catdid=1\&artid=20110112richB002>.

(Accessed: 12 January 2011).

Note 43. Kao, Thun-yun, Director of Chinese Culture Recreation Tourism Association. Interview, 20 December, 2012.

Note 44. Ms. Chang, hot-spring facility owner in the Jiaoxi area. Interview. 26 March 2013.

Note 45. Ms. Lu, souvenir retailer in Taipei. Interview, 25 February 2013.

Note 46. Mr. Hsu, consultant of THE CARLTON hotel chain. Interview, 14 June 2012.

Note 47. Ms. Chung, secretary of Catering Dept. of Hotel Royal Taipei. Interview, 16 August, 2012.

Note 48. Mr. Shi, Deputy Manager of Pyramid International T/S Co. Interview, 13 May 2012.

Note 49 .Mr. Chuang, senior supervisor at Taipei Fullerton Hotels. Interview, 17 September 2012.

Note 50. Mr. Hsu, consultant of THE CARLTON hotel chain. Interview, 14 June 2012.

Note 51. Mr. Chuang, senior supervisor at Taipei Fullerton Hotels. Interview, 17 September 2012.

Note 52. A Tourism Bureau specialist. Interview, 11 March 2012.

Note 53.Mr. Cheng, senior manager of Pyramid International T/S Co. Interview, 18 October 2012.

Note 54. Sun, Huei-wen (2009). Developing Kinmen to Attract Chinese Financiers in Line with the Deregulation of Mainlanders' Self-guided Tours in Taiwan, IDN Living Travel Network. Available at $<$ http://www.idn.com.tw/currect/content.php?catdid=6\&artid=20090717rich002 $>$. (Accessed: 17 July 2009)

Note 55. Mr. Hsu, consultant of THE CARLTON hotel chain. Interview, 14 June 2012.

Note 56. Mr. Cheng, senior manager of Pyramid International T/S Co. Interview, 18 October 2012.

Note 57. Wu, Ming-jun (2010). How Chinese People's Self-guided Tours in Taiwan are Closely Linked to the Taiwanese Tourism Sector, Liberty Available at $<$ http://www.idn.com.tw/news/news_content.php?catid=4\&catsid=5\&catdid=1\&artid=20101231 sarlin005> 
(Accessed: 12 December 2010).

Note 58. Mr. Huang, owner of Very Taipei Bridal Photography Co. Interview, 28 May 2013.

Note 59. A Tourism Bureau specialist. Interview, 11 March 2012.

Note 60. Mr. Chang, hot-spring facility owner. Interview, 26 March 2013.

Note 61. Mr. Yen, senior manager of Star Travel Co. Interview. 15 July 2012.

Note 62. A Tourism Bureau specialist. Interview, 25 February 2013.

Note 63. Su, Yong-yao (2009). It is Unwise for Taiwanese Tourism Sector to Scare Away Non-Chinese Visitors while Luring Mainlanders, Liberty Times, 1 November, p. A2.

Note 64. World Tourism Organization (2007). Handbook on Tourism Market Segmentation-Maximizing Marketing Effectiveness. Madrid: World Tourism Organization.

Note 65. Mr. Shi, Deputy Manager of Pyramid International T/S Co. Interview, 13 May 2012.

Note 66. A Tourism Bureau specialist. Interview, 11 March 2012.

Note 67. Ms. Chang, hot-spring facility owner in the Jiaoxi area. Interview. 26 March 2013.

Note 68. Ms. Lu, souvenir retailer in Taipei. Interview, 25 February 2013.

Note 69. Mr. Hsu, consultant of THE CARLTON hotel chain. Interview, 14 June 2012.

Note 70. Mr. Chang, guesthouse proprietor in the Jiaoxi hot-spring area. Interview, 27 April 2013.

Note 71. Wang, Ming-chung (2009). Mainland Tourists Take Taiwan's Commercial Activities Back to 2-decade-ago Level, The Independence Evening Post. Available at $<$ http://www.idn.com.tw/news/news_content.php?catid=4\&catsid=5\&catdid=1\&artid=20090518charles001> (Accessed: 18 May 2009).

Note 72. Lee, Ching-sung (2011). Improve Mainlanders' Self-guided Tours in Taiwan by Dividing Labor and Powers between Central and Local Governments, The Independence Evening Post. Available at $<$ http://www.idn-news.com/currect/content.php? catdid=1\&artid=20110130richA001 $>$. (Accessed: 30 January).

Note 73. Professor Chang from Shih Chien University. Interview, 13 January 2013.

Note 74. Kao, Thun-yun, Director of Chinese Culture Recreation Tourism Association. Interview, 20 December 2012.

Note 75. Ke, An-tsung (2010). China-Based HENGDELI to Pay Record-Breaking NT\$ 5.5666 Mil Per Ping for Taipei Storefront, The Independence Evening Post, 11 November, p.A20.

Note 76. Mr. Yen, senior manager of Star Travel Co. Interview. 15 July 2012.

Note 77. Mr. Hsu, consultant of THE CARLTON hotel chain. Interview, 14 June 2012.

Note 78. Mr. Hsu, lecturer from a northern Taiwan university's Department of Tourism and Hospitality. Interview. 19 Novermber 2012.

Note 79. Wu, Ming-jun (2010). How Chinese People's Self-guided Tours in Taiwan are Closely Linked to the Taiwanese Tourism Sector, Liberty Times. Available at $<$ http://www.idn.com.tw/news/news_content.php?catid=4\&catsid=5\&catdid=1\&artid=20101231 sarlin005>

(Accessed: 12 December 2010).

Note 80. Anonymous author (2010). Meng Xiaosu: Deregulation of Chinese People's Self-guided Tours in Taiwan Lures Chinese Financiers. Available at <http://www.haixiainfo.com.tw/128100.htmll . (Accessed: 13 December 2010).

Note 81. Liou, Hsuan-tung (2009). Chinese Buyers Snatch up Taiwanese Housing Market before Legalization of Mainlanders' Self-guided Tours in Taiwan, online edition of China Times. Available at $<$ http://mag.chinatimes.com/mag-cnt.aspx?artid=671>. (Accessed: 10 May 2009).

Note 82. Professor Chang from Shih Chien University. Interview, 13 January 2013.

Note 83. A Tourism Bureau specialist. Interview, 11 March 2012.

Note 84. Professor Chang from Shih Chien University. Interview, 13 January 2013 